\title{
LATE MIOCENE VEGETATION RECONSTRUCTION WITH THE CARAIB MODEL
}

Louis François ${ }^{1}$, Dominique Otto ${ }^{1}$, Frédéric Fluteau ${ }^{2}$ and Arne Micheels ${ }^{3}$

$\left({ }^{1}\right)$ Laboratoire de Physique Atmosphérique et Planétaire, Université de Liège, 5 avenue de Cointe, B-4000 Liège, Belgium. E-mails: francois@astro.ulg.ac.be, otto@astro.ulg.ac.be

$\left({ }^{2}\right)$ Institut de Physique du Globe de Paris, 4 Place Jussieu, F-75252 Paris Cedex 05, France. E-mail: fluteau @ ipgp.jussieu.fr

$\left({ }^{3}\right)$ Institut und Museum für Geologie und Paläontologie, Eberhard Karls Universität Tübingen, Sigwartstrasse 10, D-72076 Tübingen, Germany.

E-mail: arne.micheels@uni-tuebingen.de

The CARAIB (CARbon Assimilation In the Biosphere) model is a global terrestrial biosphere model which was originally developed to study the biosphere contribution to the global carbon cycle. The primary purpose of the model is hence the calculation of the $\mathrm{CO}_{2}$ exchange flux between the vegetation-soil system and the atmosphere. The model is composed of 5 main modules describing (1) soil hydrology, (2) stomatal regulation and photosynthesis, (3) carbon allocation, growth and autotrophic respiration, (4) litter/soil carbon storage and heterotrophic respiration, and (5) competition of plant functional types (PFTs) and biomisation (biogeography). The latest module implemented into CARAIB is the biogeography module. To simulate the competition of trees and grasses, two vegetation storeys have been introduced in the canopy submodel. This allows us to determine the light available to grasses as a direct function of the leaf area index (LAI) of the tree canopy. Both of these storeys are potentially composed of several PFTs. The cover fraction of each PFT within each storey is estimated according to its respective net primary productivity (NPP). A biome is assigned to each grid cell on the basis of the PFTs present, their relative abundances and a limited set of climatic criteria.

The model is able to reproduce the broad-scale patterns of the modern distribution of potential vegetation. It has been applied to reconstruct the vegetation and the terrestrial carbon stocks at the last glacial maximum (21 ky BP). Here, we use the model to reconstruct the Late Miocene (Tortonian) vegetation. For this reconstruction, CARAIB has been forced with climatic outputs from two different general circulation models, LMD and ECHAM. The two simulations are compared in terms of vegetation distribution and carbon storage. 